\title{
Impact of crop protection strategies on natural enemies in organic apple production
}

\author{
Gaëlle Marliac • Servane Penvern • Jean-Marc Barbier • \\ Françoise Lescourret • Yvan Capowiez
}

Accepted: 12 January 2015 / Published online: 30 January 2015

(C) INRA and Springer-Verlag France 2015

\begin{abstract}
Organic farming is mainly viewed as a homogeneous production system. Organic farming is also commonly thought to favor natural enemies of pests for crop protection. However, organic farming involves very different management practices and, in turn, various protection strategies. There is little knowledge on the influence of protection strategies on natural enemies in organic agriculture. Here, we analyzed crop protection strategies of 24 organic apple farmers in Southeast France. We also analyzed natural enemy communities in 12 apple orchards. We measured the impact of strategies on natural enemies using the International Organization for Biological and Integrated Control (IOBC) toxicity index. We identified four protection strategies: (1) the ecologically intensive strategy which promotes natural enemies by habitat management, (2) the substitution strategy mainly based on the use of pesticides, (3) the technologically intensive strategy which uses innovative technological methods such as exclusion nets and the integrated strategy which mobilizes a wide range of different practices. The IOBC toxicity index was $78.8 \pm 23.0$ for the substitution strategy, $60.75 \pm 15.0$ for the integrated strategy, $37.4 \pm 11.9$ for the ecological strategy, and $31.25 \pm 1.7$ for the technological strategy. We also found that the four strategies have different natural enemy communities such as the higher abundance of Forficula pubescens in the ecological strategy.
\end{abstract}

G. Marliac $(\bowtie) \cdot$ F. Lescourret $\cdot$ Y. Capowiez

INRA, UR1115 Plantes et Système de cultures Horticoles, Domaine St. Paul, Site Agroparc, 84914 Avignon Cedex 09, France

e-mail: gaelle.marliac@avignon.inra.fr

S. Penvern

INRA, Unité Ecodéveloppement, Site Agroparc, Domaine St. Paul, 84914 Avignon Cedex 09, France

J.-M. Barbier

INRA, UMR Innovation, 2 Place Pierre Viala, 34060 Montpellier

Cedex 2, France
Keywords Organic agriculture $\cdot$ Pesticides $\cdot$ Biodiversity Farm typology $\cdot$ Intensification $\cdot$ Pests

\section{Introduction}

Organic agriculture is assumed to achieve more sustainable practices by reducing environmental impacts, such as biodiversity decline, compared to conventional agriculture (Tscharntke et al. 2005). While positive links between organic agriculture and biodiversity, including natural enemy abundance, have often been reported (Bengtsson et al. 2005; Hole et al. 2005; Garratt et al. 2011; Winqvist et al. 2011), very little is known about the effects of variability in crop protection strategies within organic production systems, although this variability can be high (Letourneau and Bothwell 2008; Penvern et al. 2010; Puech et al. 2014). This may result in differential impacts on pest numbers and biological conservation and thus opens the way for the development of more ecological and sustainable protection strategies in organic farming.

Organic management strategies can be very complex as they combine, according to Wyss et al. (2005), (i) cultural practices such as fertilizer use (Grechi et al. 2008), (ii) habitat management through hedgerows (Rieux et al. 1999) and ground cover (Landis et al. 2000), (iii) use of biocontrol agents such as specific granulosis virus for insect pests (Arthurs et al. 2007), and (iv) direct control methods, i.e., pesticides authorized in organic agriculture such as spinosad (Arthurs et al. 2007) and physical methods, e.g., Alt'carpo exclusion nets. The Alt'carpo net disrupted codling moth colonization and reproduction (Sauphanor et al. 2012). The hierarchy and combination of these different practices aim to limit the development of a wide range of pests. However, while some practices, 
such as fertilizer use (Garratt et al. 2011) or habitat management (Landis et al. 2000), are known to be efficient without any secondary detrimental effects on natural enemies, others, such as pesticide usage, are known to have detrimental effects (Theiling and Croft 1988). These combinations can result in differences in pesticide use intensity, i.e., frequency and toxicity, and are likely to exert differential pressures on pests and natural enemies.

To gain further knowledge about the relationships between the variability of organic crop protection strategies and biodiversity, we conducted a survey in organic apple orchards in Southeast France. Orchards are perennial crops and offer favorable conditions for maintaining food webs within the agroecosystem and thus provide opportunities for pest natural regulation (Simon et al. 2010). However, a great number of pesticides are applied to apple orchards with, on average, 29.9 insecticide and fungicide applications in organic orchards in Southeast France each year (Sauphanor et al. 2009).

This study had two major objectives. First, we aimed to describe the variability of crop protection practices used within organic apple orchards in the region and define strategies according to the hierarchy and combinations of the different practices used. Second, we investigated the differential impacts of these strategies in terms of (i) pesticide application intensity and the estimated toxicity for natural enemies and (ii) pest infestations and the abundance and diversity of natural enemies observed in the orchards. These kinds of relationships have been previously examined in several crops but are often limited to comparisons between organic and conventional production (Bengtsson et al. 2005; Hole et al. 2005; Garratt et al. 2011; Winqvist et al. 2011). Studying such different cropping systems is likely to provide clear answers but neglects the variability of practices encountered within each cropping system and does not allow the separate effects of each practice to be investigated. To our knowledge, the present study is the first to specifically address the variability of pest management practices implemented within organic production systems and to assess their effects on pest populations and natural enemy diversity and abundance.

\section{Materials and methods}

\subsection{Study area and survey}

The study was carried out around Avignon, in Southeast France, where $24 \%$ of French apple orchards are concentrated (Agreste 2014) and $4 \%$ of this area has been converted to organic agriculture (Agence bio 2012). In the selected orchards, soils were calcosols of similar geological origin, e.g., deposits from the Rhône and Durance rivers. The average annual temperature is about $14.7^{\circ} \mathrm{C}$, at the height of summer the temperature rises to $30^{\circ} \mathrm{C}$. The average rainfall is $465 \mathrm{~mm} /$ year. Insecticides are used against two major pests: (i) the codling moth Cydia pomonella (L.) (Lepidoptera: Tortricidae) and (ii) the rosy apple aphid Dysaphis plantaginea (Passerini) (Hemiptera: Aphididae) (Sauphanor et al. 2009). In organic agriculture, insecticides are not used to target other pests such as phytophagous mites (Sauphanor et al. 2009). These two pests have different life cycles but share some natural enemies.

We selected and surveyed 24 organic apple farmers identified by local experts (technical advisors of the Chamber of Agriculture and advice organizations) to represent the widest range of crop protection strategies in Southeast France. Semistructured interviews were carried out from January to March 2012. We collected data about the farms: farmers' conversion date to organic agriculture, farm size, apple orchard surface area, system of commercialization, and conventional and organic mixity within the farm; and about their crop protection management at the farm level. The questionnaire aimed to identify all practices implemented by the farmers to limit pest infestations and promote natural enemies.

\subsection{Description of crop protection strategies}

Among the practices known or assumed to have effects on the two major pests and their natural enemies, the discriminant practices were coded using qualitative descriptors. Eleven descriptors were selected to reflect the diversity of the farming practices related to crop protection: application of spinosad against codling moth (yes or no) (1), pyrethrine against rosy apple aphid (yes or no) (2), application of kaolin clay (yes or no) (3), application of homemade herbal teas (yes or no) (4), use of Alt'Carpo net exclusion (three classes, $0 \%$, less or more than $50 \%$ of the area covered by Alt'Carpo exclusion net) (5), application of $C$. pomonella granulosis virus (yes or no) (6), kind of hedgerow planted (two classes: windbreak monospecific hedgerow or composite hedgerow) (7), ground cover management (two classes: ground cover mowed in all alleys or mowed only on alley out of two) (8), area planted with scab- and rosy apple aphid-resistant cultivars (four classes: $0,1-20,20-60$, more than $60 \%$ of the area covered by resistant varieties) (9), management of tree vigor (yes or no) and (10) type of thinning method (three classes: sulfur application; sulfur application and manual thinning; manual thinning) (11). The use of mating disruption was not sufficiently discriminating since it was systematically coupled with the use of $C$. pomonella granulosis virus except in two cases where the minimum orchard surface area, required for efficient mating disruption, were not met.

Multiple correspondence analysis was used to analyze the set of qualitative descriptors (Lebart et al. 1997). The multiple correspondence analysis allowed us to reduce the number of descriptors by converting the matrix of data into a limited number of factors. Based on the visual inspection of the 
eigenfactors, the three first factors were retained and explained $52.67 \%$ of the inertia. The correlation coefficient between each descriptor and factor in the multiple correspondence analysis was calculated for each factor (Chessel et al. 2004).

The 24 farms were identified by their coordinates on these three axes and were then submitted to an ascending hierarchical classification using Ward's (Ward 1963) algorithm of aggregation by variance in order to make four homogeneous groups. To test the significance of the identified groups, we used a between-class analysis (Chessel et al. 2004) followed by a randomization procedure with 99 permutations. For visualization, variance ellipses were drawn around each group on the multiple correspondence analysis projection planes. The position of each crop protection strategy on these projection planes and the correlation ratio with each descriptor allowed us to define different crop protection strategies according to their combination of practices.

We tested the relations between potential determinant factors on the adoption of the crop protection strategy: farmers' conversion date to organic agriculture, apple surface area, organic surface area, commercialization system, and coexistence of organic and conventional area on the farm. We also performed a multiple correspondence analysis (Lebart et al. 1997) on this determinant dataset. This was again followed by a between-class analysis (Chessel et al. 2004) and a randomization procedure with 99 permutations to test the significance of the groups. Since none of these determinants showed a significant difference between the four protection strategies, these results are not shown.

\subsection{Impact assessment of protection strategies}

\subsubsection{Pesticide use and estimated toxicity}

Treatment calendars for the 2012 season were collected. All pesticide applications were assumed to be at the regulatoryrecommended spray rate and concentration, full block and row by row spraying unless noted otherwise by the farmers. The treatment frequency index was calculated using the following formula: $\mathrm{TFI}=\Sigma(\mathrm{AD} / \mathrm{HD})$, where $\mathrm{AD}$ is the amount of pesticide applied in a field per hectare and HD is the recommended rate per hectare (Jørgensen 1999). Four types of treatment frequency index were calculated, one per pesticide type used in organic farms: fungicides, $C$. pomonella granulosis virus, other insecticides, and a total treatment frequency index which is the sum of the three other treatment frequency indices. The fungicides used were copper and sulfur; other insecticides used were spinosad, pyrethrines, and mineral oils, and no herbicides were applied in the organic farms.

To estimate the toxicity of each pesticide, we used the database of pesticide toxicity on natural enemies developed by the International Organization for Biological and Integrated Control (IOBC, http://www.iobc-wprs.org/). In this database, a toxicity class has been assigned to each pesticide on a scale of 1-4 from lowest to highest mortality. We calculated cumulative IOBC toxicity scores for each orchard, the IOBC toxicity index, using the following formula: $\sum\left(\mathrm{TFI}_{\text {Pesticide }} \times\right.$ toxicity), where $\mathrm{TFI}_{\text {Pesticide }}$ is the treatment frequency index of one pesticide, and toxicity is the toxicity class of this pesticide (Thomson and Hoffmann 2006).

The homogeneity of variance and normality were verified using Bartlett's and Shapiro-Wilk tests, respectively. We determined the relationship between the crop protection strategies and the four TFI indexes and the IOBC index using a oneway ANOVA followed by post hoc comparisons (Tukey HSD) when normality and homoscedasticity were met. Otherwise, Kruskal-Wallis analyses followed by post hoc comparison tests were performed. The significance level was set to $5 \%$.

\subsubsection{Efficacy of pest control and impact on the natural enemy community}

Pest infestation and natural enemy communities were monitored in a subset of 12 orchards chosen randomly among each crop protection strategy identified using the method described in Section 2.2. Only one orchard per producer was monitored and was chosen according to protection strategy correspondence, apple variety, and geographic proximity. The major characteristics of each apple orchard monitored were apple variety, irrigation, Alt'Carpo net, plot size, number of fungicide, $C$. pomonella granulosis virus $(C p G V)$, and insecticides (shown in Table 2). All the orchards had a spontaneous ground cover. The flower density was monitored qualitatively at three sampling dates, and no significant differences were observed between the orchards.

To monitor rosy apple aphids, the number of infested trees, i.e., bearing at least one rosy apple aphid colony, was counted per orchard and per date on 30 randomly selected trees. Five observation dates were recorded from mid-April until June 2012 every fortnight. We derived a cumulative index of infestation (IF) indicating the proportion of infested trees per season and per orchard:

$\mathrm{IF}=$ number of infested trees during the season /

number of trees observed during the season.

C. pomonella abundance was monitored at the end of the 2012 season by counting diapausing larvae in 30 corrugated cardboard band traps wrapped around tree trunks, at $50 \mathrm{~cm}$ above the ground level, in each orchard (Monteiro et al. 2013). The band traps were installed in mid-July 2012 and collected at the end of October in that year.

The abundance and diversity of natural enemies were estimated throughout the periods when rosy apple aphid and 
codling moth are present, i.e., six times from mid-April to the end of August, on the 24th of April, 2nd of May, 10th of May, 4th of June, 19th of July, and 22nd of August. In each orchard, corrugated cardboard band traps were wrapped around one branch at a height of 1.20-1.50 $\mathrm{m}$ above ground level of the 30 randomly selected trees. The traps were $10-\mathrm{cm}$ wide and $20-\mathrm{cm}$ long, with 13 corrugations per $10 \mathrm{~cm}$ (Simon et al. 2011; Pekár 1999). The traps were left for 15 days. Arthropods found in the band traps were stored in $70 \%$ ethanol for further identification. According to their relative abundance, we defined different observable taxonomic units (OTU) as earwig populations were described at the species level (Dermaptera: Forficula auricularia and Forficula pubescens) and spiders at the family level (Araneae, mainly Salticidae, Gnaphosidae, Miturgidae, Thomisidae), while Coccinellidae (Coleoptera, mainly Adalia bipunctata L. and Harmonia axyridis P.) and Chrysopidae (Nevroptera, Chrysoperla spp., and Hemerobius spp.) were grouped at order level. As larvae of all these natural enemies are also predators, we pooled those counts with those of adults. For statistical analysis, the six samples were pooled in two groups: the samples taken during the rosy apple aphid infestation and samples taken after the rosy apple aphid infestation, i.e., before the 15th of June and after the 15th of June.

We calculated four common indices to characterize the natural enemy community, expressed as OTUs per orchard: (i) abundance $(N)$; (ii) richness as OTUs; and (iii) the Shannon diversity index (H) (Oksanen et al. 2007):

$H=-\sum \mathrm{pi} \times \log _{2}(\mathrm{pi})$

where pi is the proportional abundance of the OTUi and (iv) the evenness index $(E)$ :

$E=\sum \frac{H}{\log _{2} S}$

where $S$ is the OTU richness.

We performed principal component analysis (Borcard et al. 2011) on the pest infestation and natural enemy dataset. This was again followed by a between-class analysis (Chessel et al. 2004) and a randomization procedure with 99 permutations to test the significance of the crop protection strategies. For visualization, variance ellipses were drawn for each group on the between-class projection plane (defined by the two first factors).

All statistical analyses were performed using R software ( $R$ Development Core Team 2010): multiple correspondence analysis, principal component analysis, ascending hierarchical classification, and between-class analysis were performed with the package Ade4 (Chessel et al. 2004), and the indices to characterize the natural enemy community were calculated with the Vegan package (Oksanen et al. 2007).

\section{Results and discussion}

\subsection{Variety of practices used by organic apple farmers}

Analysis of the results of the farmer surveys identified the variety of practices used to control pests and promote natural enemies. These practices involve very different types of action. Some practices favor bottom-up regulation by controlling pest development through resource availability: (i) the management of tree vigor through fertilization management; (ii) the choice of apple cultivar, e.g., Juliet ${ }^{\mathbb{R}}$ a new cultivar, available for organic orchards only, which is resistant to scab and tolerant to the rosy apple aphid; and (iii) manual thinning to limit codling moth populations. Previous studies reported the effect of vigor management on aphid development (Grechi et al. 2008) and the efficiency of tolerant aphids or resistant apple scab varieties towards these pests.

Other practices, such as habitat management, are aimed at promoting natural enemies in order to maximize top-down regulation, i.e., pest population reduction by natural enemies. Some farmers planted composite hedgerows (with multispecies composition), which are thought to favor natural enemies more than mostly monospecific Cupressus spp. windbreak hedgerows (Rieux et al. 1999). Some farmers manage the ground cover; they move only one orchard alley out of two in order to limit physical disturbances and keep flowers in the orchard to provide floral resource subsidies, alternative hosts, and prey to attract natural enemies.

Some practices directly target pests, such as the application of homemade herbal teas, used in biodynamic agriculture (Tassoni et al. 2013), or C. pomonella granulosis virus or Bacillus thuringiensis combined with mating disruption and spinosad and pyrethrines. Spinosad was applied according to technical recommendations, whereas pyrethrine was applied according to the phenological stage of apple tree. In addition, repellent agents such as kaolin are sprayed onto leaves as physical barriers (Markó et al. 2008). The Alt'Carpo exclusion net can also be listed in this category, as it provides physical protection against pest colonization and reproduction (Sauphanor et al. 2012) (Fig. 1). These nets have increasingly been used since 2005 in Southeast France for controlling populations of codling moth (Sauphanor et al. 2012).

\subsection{Typology of crop protection strategies}

The first factor of the multiple correspondence analysis was defined by $C$. pomonella granulosis virus application (ratio correlation, 0.67), area covered by Alt'Carpo net exclusion $(0.53)$, and the area covered by resistant variety $(0.41)$. The management of ground cover (0.56) and the codling moth insecticide application (0.45) defined the second factor. Homemade herbal tea application (0.39), kind of hedge 
Fig. 1 Pictures of one inter-row of organic apple orchards without (a) or with (b) Alt'Carpo exclusion nets

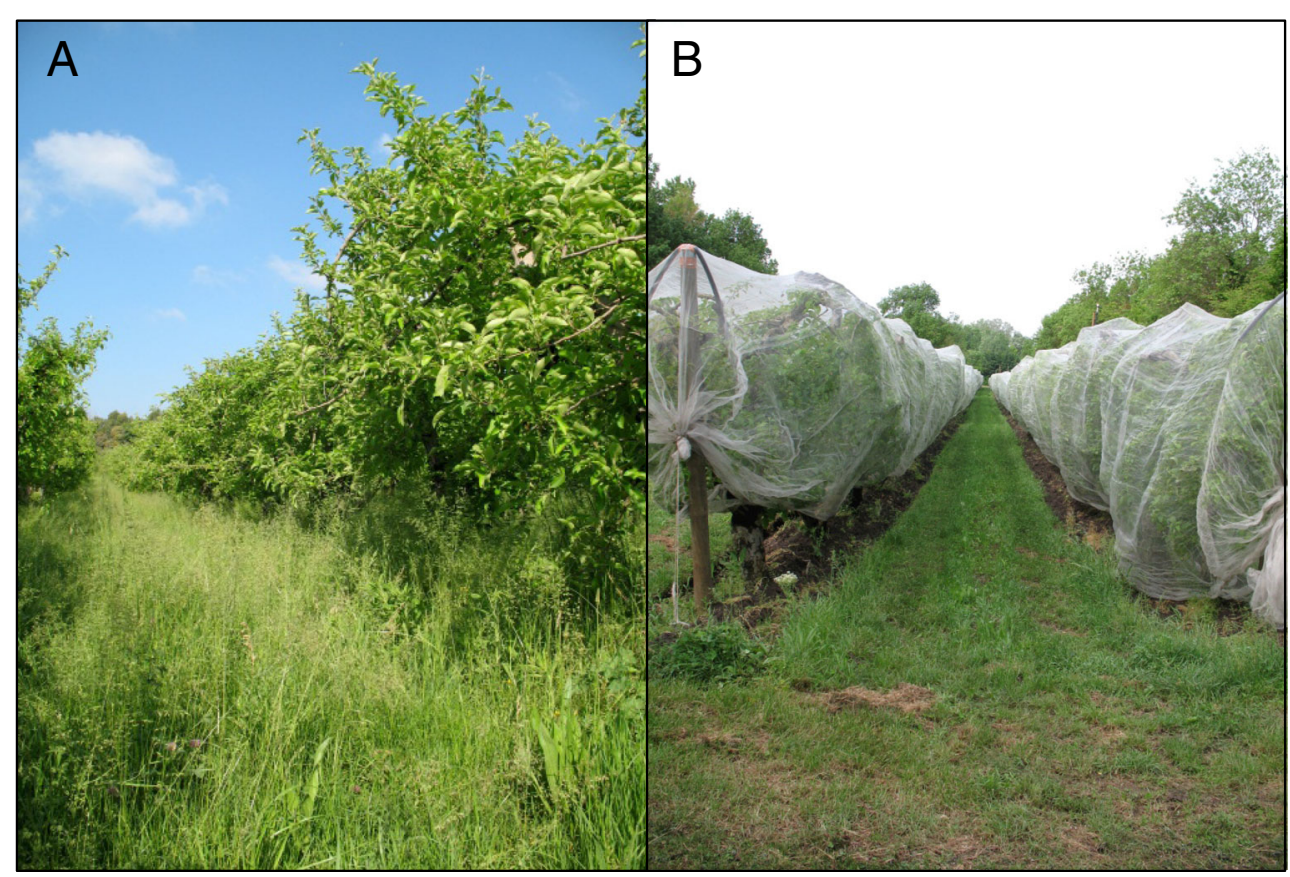

(0.35), and management of tree vigor (0.33) defined the third factor (Fig. 2 and Table 1).

The four crop protection strategies defined by the hierarchical classification were significantly different $(P=0.001$; between-class analysis). The technologically intensive strategy, on the right of the first axis, relies on the use of recent technological methods. All organic orchards in this strategy were covered by Alt'Carpo nets and planted with the new resistant variety Juliet ${ }^{\mathbb{}}$. These farmers did not manage the habitat in order to promote natural enemies: all the orchard alleys were mowed and monospecific hedgerows were planted as windbreak only (except for one farm) (Table 1). This strategy has not yet been described in the literature and is here shown to be characterized by a limited combination of practices and a focus on recent technological methods.

Farmers implementing the ecologically intensive strategy, at the top of the second axis, differed from the others due to the importance given to ecologically sound practices. They managed habitats to promote natural enemies by mowing only one orchard alley out of two and planting composite hedgerows, only one farmer planted a windbreak hedgerow. In addition, these farmers reduced environmental impacts by using C. pomonella granulosis virus instead of spinosad against codling moth (Table 1). This strategy is consistent with the original approach of organic agriculture that promotes indirect or preventive measures (Wyss et al. 2005). In addition, two of the farmers relying on this strategy followed the principles of biodynamic agriculture. The main difference with organic agriculture is the use of biodynamic preparations which contain specific herbs or minerals, treated or fermented with animal tissues (Tassoni et al. 2013). Several authors have discussed biodynamic agriculture as a distinct system from organic production systems (Pfiffner and Niggli 1996; Tassoni et al. 2013). However, to our knowledge, the organic crop protection strategies and consequences on natural enemies and biological control of biodynamic agriculture have not yet been characterized enough to be clearly separated from organic production.

Farmers using the integrated strategy implemented the largest combination of practices to control pests and minimize impacts on natural enemies. They controlled tree vigor and preserved composite hedgerows. To manage codling moth, they used various methods such as C. pomonella granulosis virus, spinosad, and Alt'Carpo exclusion nets (Table 1). This kind of strategy was described in previous studies (Letourneau and Bothwell 2008; Penvern et al. 2010) and is consistent with the definition of integrated pest management in orchards (Brown 1999). However, farmers did not rely on treatment thresholds to decide pesticide application, whereas it is the basis of IPM. This may be related to the limitations in directly controlling pests and diseases with organic products: due to the lower efficacy of most organic registered products, strategies are much more preventive than curative (Simon et al. 2011).

Farmers using the substitution strategy also relied on a limited combination of practices mostly directly targeted towards pests. Against codling moth, they used a combined approach: spinosad, $C$. pomonella granulosis virus, or exclusion nets (Table 1). However, compared to the previous strategy, they did not manage the habitat to promote natural enemies: all the orchard alleys were mowed and only windbreak hedgerows were planted. After conversion to organic 
Fig. 2 Projections of each farm on the first and second axis (a) and first and third axis (b) of the multiple correspondence analysis. Each crop protection strategy is indicated by a variance ellipse (67\%). The descriptors for each pest management practice are projected. a The first factor distinguished, on the left side, increased area covered by resistant variety (Var.2) and by Alt'carpo net exclusion (Net.2) that characterized the technologically intensive strategy and, on the right side, the use of C. pomonella granulosis virus (GV.1). The second axis opposed, on the top, the management of ground cover (Cover. 1) and the absence of spinosad application (CM.O) what distinguished the ecologically intensive from the integrated and substitution strategy. b The third factor opposed the use of homemade herbal teas (Tea.1), management of tree vigor (Vig. 1), and Hedge type (Hedge.2) that distinguished the integrated strategy from the three others

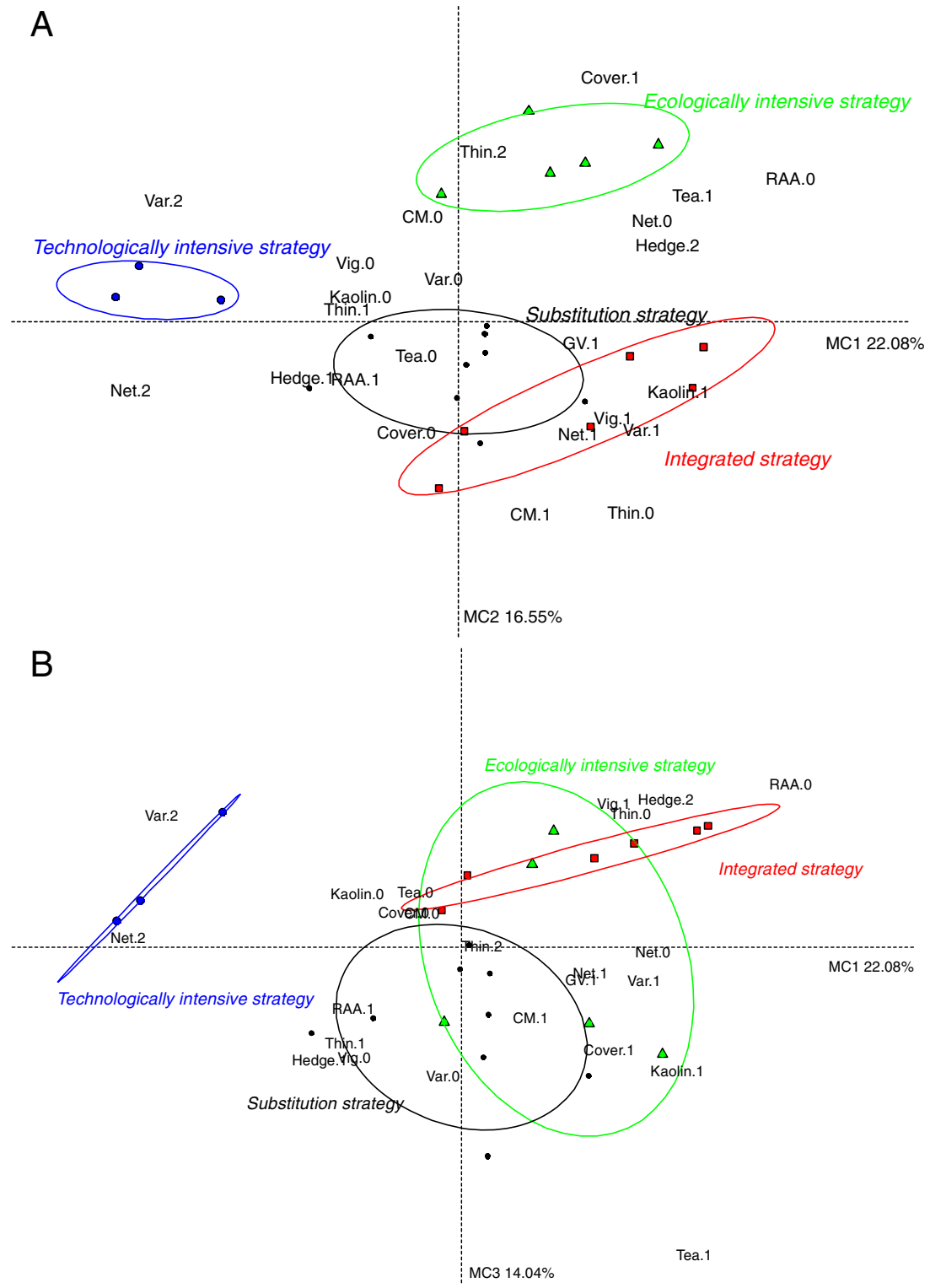

Farmer characteristics, such as education level, experience in agriculture, decision support systems, as well as the known efficacy of methods available to control pests, may determine the protection practices and strategy they adopt (Hubbell and Carlson 1998; Lohr and Park 2002). However, in our study, none of these factors was clearly correlated with any of the four groups.

\subsection{Links between crop protection strategies and pesticide use}

Within our organic orchards, pesticide usage was high and varied significantly: treatment frequency indices ranging from 10 to 61 per season. The average treatment frequency index (23.98 per season) was consistent with the mean values previously reported in the same area (Sauphanor et al. 2009; 
Table 1 For each implemented practice, correlation ratio is presented with the three first factors of multiple correspondence analysis and the number of farmers in each class

\begin{tabular}{|c|c|c|c|c|c|c|c|}
\hline & \multicolumn{3}{|c|}{ Correlation ratio } & \multicolumn{4}{|c|}{ Crop protection strategy } \\
\hline & $\begin{array}{l}\text { First } \\
\text { factor }\end{array}$ & $\begin{array}{l}\text { Second } \\
\text { factor }\end{array}$ & $\begin{array}{l}\text { Third } \\
\text { factor }\end{array}$ & $\begin{array}{l}\text { Ecologically } \\
\text { intensive } \\
\text { ( } 5 \text { farmers })\end{array}$ & $\begin{array}{l}\text { Integrated } \\
\text { (6 farmers) }\end{array}$ & $\begin{array}{l}\text { Substitution } \\
\text { (9 farmers) }\end{array}$ & $\begin{array}{l}\text { Technologically } \\
\text { intensive ( } 4 \text { farmers) }\end{array}$ \\
\hline Codling moth insecticide application (yes or no) & 0.02 & 0.45 & 0.05 & $0: 5$ & $2: 4$ & $5: 4$ & $0: 4$ \\
\hline Rosy apple aphid insecticide application (yes or no) & 0.34 & 0.16 & 0.20 & $2: 3$ & $3: 3$ & 9:0 & $4: 0$ \\
\hline C. pomonella granulosis virus application (yes or no) & 0.67 & 0.02 & 0.08 & $5: 0$ & $6: 0$ & $9: 0$ & $0: 4$ \\
\hline Homemade herbal teas (yes or no) & 0.10 & 0.08 & 0.39 & $2: 3$ & $0: 6$ & $1: 8$ & $0: 4$ \\
\hline Kaolin application (yes or no) & 0.22 & 0.04 & 0.15 & $1: 4$ & $2: 4$ & $5: 4$ & $0: 4$ \\
\hline $\begin{array}{l}\text { Alt'Carpo net exclusion }(0 \% \text {, less or more than } \\
50 \% \text { of the area covered) }\end{array}$ & 0.53 & 0.18 & 0.003 & $5: 0: 0$ & $2: 2: 2$ & $3: 4: 2$ & $0: 0: 4$ \\
\hline $\begin{array}{l}\text { Resistant variety }(0,1-20,20-60 \text {, more than } \\
60 \% \text { of the area covered by resistant varieties })\end{array}$ & 0.41 & 0.21 & 0.19 & $2: 1: 2$ & $1: 5: 0$ & $2: 6: 1$ & $0: 0: 4$ \\
\hline Tree vigor management (yes or no) & 0.15 & 0.13 & 0.33 & $1: 4$ & $6: 0$ & $2: 7$ & $1: 3$ \\
\hline $\begin{array}{l}\text { Thinning (sulfur application; sulfur application } \\
\text { and manual thinning; manual thinning) }\end{array}$ & 0.14 & 0.38 & 0.20 & $0: 2: 3$ & $5: 0: 1$ & $2: 6: 1$ & $0: 3: 1$ \\
\hline Hedge (windbreak hedgerow or composite hedgerow) & 0.26 & 0.10 & 0.35 & $1: 4$ & $1: 5$ & $9: 0$ & $3: 1$ \\
\hline $\begin{array}{l}\text { Management of ground cover (mowed in all } \\
\text { alleys or mowed only on alley out of two) }\end{array}$ & 0.08 & 0.56 & 0.08 & $0: 5$ & $6: 0$ & $7: 2$ & $4: 0$ \\
\hline
\end{tabular}

Significant correlation ratios are indicated in bold. C. pomonella granulovirus application, area covered by Alt'Carpo net exclusion, area covered by resistant variety defined the first factor of the multiple correspondence analysis. The management of ground cover and the codling moth insecticide application defined the second factor. Homemade herbal tea application, hedge type, and management of tree vigor defined the third factor. For each crop protection strategy, the number of farmers implemented the modality of crop protection practice was done

data in italics are the different modalities for each practice

Monteiro et al. 2013). This resulted in high values for the IOBC toxicity index, which ranged from 27.5 to 125 (Fig 3).

The total treatment frequency index for the technologically intensive strategy was significantly lower than for the other three crop protection strategies (Kruskal-Wallis, chi $^{2}=13.18$, $d f=3, P=0.004$ ) (Fig. 3). This lower total treatment frequency index in the technologically intensive strategy is related to its significantly lower treatment frequency index for C. pomonella granulosis virus compared to the ecologically intensive, integrated and substitution strategies (KruskalWallis, chi $^{2}=0.4175, d f=3, P=0.02$ ) and to its significantly lower fungicide treatment frequency index compared to the
Fig. 3 Treatment frequency indexes and International Organization for Biological and Integrated Control $(I O B C)$ index/ 2 for each organic crop protection strategy (mean \pm standard deviation). The technologically intensive strategy had a lower total treatment frequency index than the three other strategies. The IOBC index was higher in substitution strategy than in ecologically and technologically intensive strategies

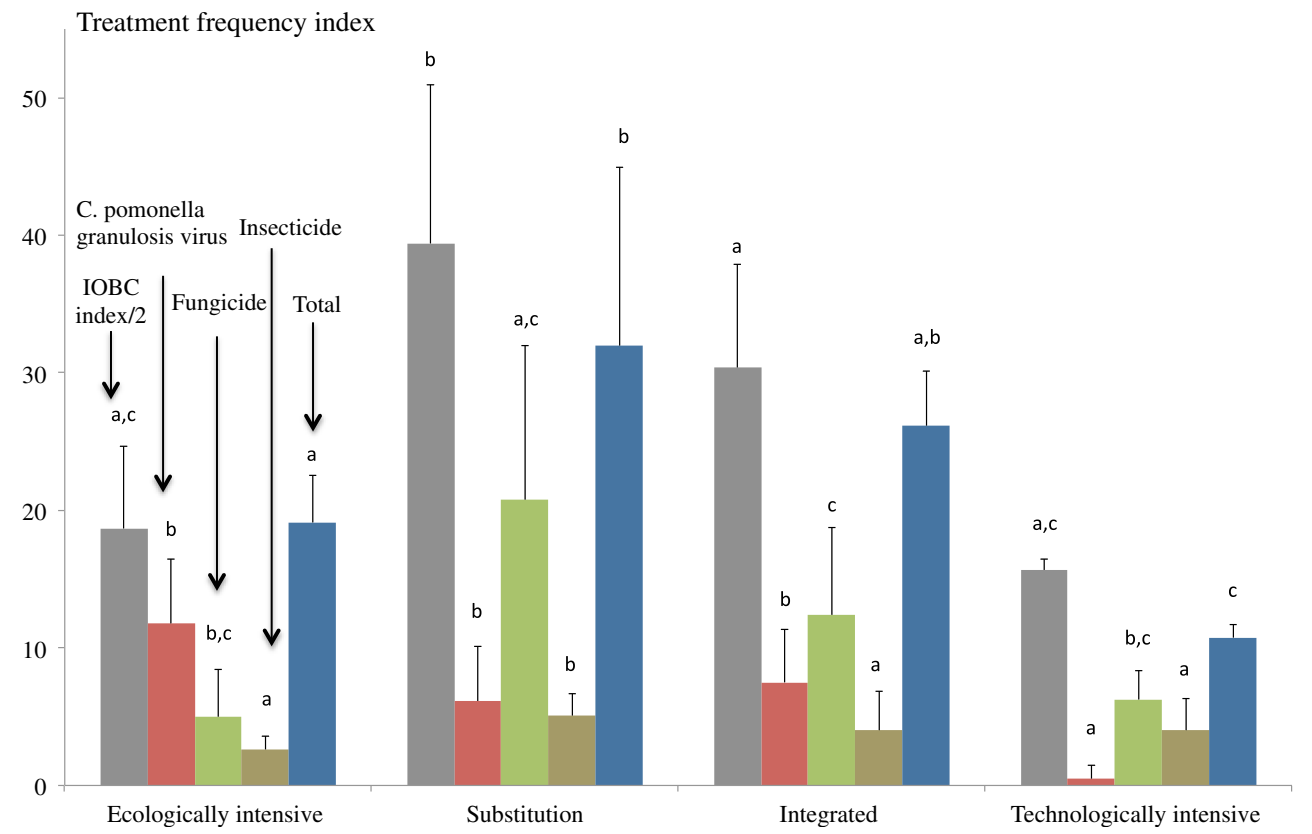


substitution and integrated strategies (Kruskal-Wallis, chi $^{2}=$ 12.10, $d f=3, P=0.007)$. The installation of Alt'Carpo net exclusion reduced $C$. pomonella granulosis virus usage (Sauphanor et al. 2012). The decreased reliance on fungicides was due to the use of resistant cultivars as previously reported in annual crops by Bürger et al. (2012) and in apple orchards by Simon et al. (2011).

The Ecologically intensive strategy also resulted in a lower fungicide treatment frequency index. This may be due to farmers having a higher tolerance. Despite the variability observed among strategies, the insecticide treatment frequency index was not significantly different between the protection strategies (Kruskal-Wallis, $\operatorname{chi}^{2}=4.7379, d f=3, P=0.19$ ).

The IOBC index was significantly higher in the substitution and integrated strategies than in the ecologically and technologically intensive strategies (Kruskal-Wallis, $\mathrm{chi}^{2}=$ $13.1305, d f=3, P=0.004363)$. The IOBC toxicity index was linked to the treatment frequency index and pesticide choice. Farmers choose insecticides based on their toxicity towards natural enemies but mostly by taking into account the efficiency against the targeted pests and/or user safety (Hubbell and Carlson 1998). Thus, pesticide choice can reduce the impacts on natural enemies, as shown by integrated pest management compared to conventional strategies (Suckling et al. 1999).

3.4 Links between crop protection strategies, pest infestation, and natural enemies

The two first axes of the between-class analysis explained $89.9 \%$ of the inertia (69.9 and $28.0 \%$, respectively). The permutation test indicated a significant difference between the crop protection strategies according to the natural enemy community and pest infestation present $(P$ value $=0.01)$ (Fig. 4 and Table 2). The first axis of the between-class analysis was mainly characterized by pest infestation, especially rosy apple aphid, and Coccinellidae abundance at the right side of the axis and $F$. auricularia and Salticidae abundance on the other side. The integrated, substitution, and technologically intensive strategies were distributed along this axis. In the integrated strategy, on average, 51.98 rosy apple aphid colonies were counted per tree, whereas 0.71 or 17.13 colonies were observed in the technology intensive strategy and substitution strategy, respectively. On average, 0.18 Coccinellidae per trap were present in the integrated strategy, while in the three other strategies, abundances were much lower with $0.03,0.01$, and 0 for the ecologically intensive, substitution, and integrated strategies, respectively. The higher Coccinellidae abundance was related to the presence of aphids (Piñol et al. 2009) since female ladybirds prefer to lay eggs on aphid-infested trees where their larvae perform best (Rana et al. 2002). The second axis of the between-class analysis, characterized by the abundance of $F$. pubescens at the top, segregated the ecologically intensive strategy from the substitution strategy. On average, $0.99 F$. pubescens per trap was observed in the ecologically intensive strategy compared to $0.06,0.02$, and 0.09 individual per trap in the substitution, integrated, and technologically intensive strategies, respectively. F. pubescens may be a bioindicator of orchards with low pesticide use.

Despite significant differences in natural enemy abundance and diversity between the four crop protection strategies, the distinction was less pronounced than that previously observed when conventional and organic agriculture were compared in annual crops (Bengtsson et al. 2005; Hole et al. 2005). Beyond obvious differences in pesticide use, this can be related to characteristics specific to orchards. Orchards are perennial habitat which enhances the stability of the system and its resilience (Brown 1999; Simon et al. 2010). Orchards are multi-strata habitats with a diversity of plant/pest resources in the ground cover providing resources, shelter, and habitat for natural enemies (Landis et al. 2000), and intra-guild
Fig. 4 Projections of each farm on the first and second axis of the between-class analysis. Each crop protection strategy is indicated by a variance ellipse $(67 \%)$. The index of the natural enemy community is projected on the first and second axis of the between-class analysis. The first factor separated, on the left, rosy apple aphid infestation and Coccinellidae abundance, higher in the integrated strategy compared to the three others. The second factor separated, on the top, F pubescens abundance, higher in the ecologically intensive strategy compared to the three others

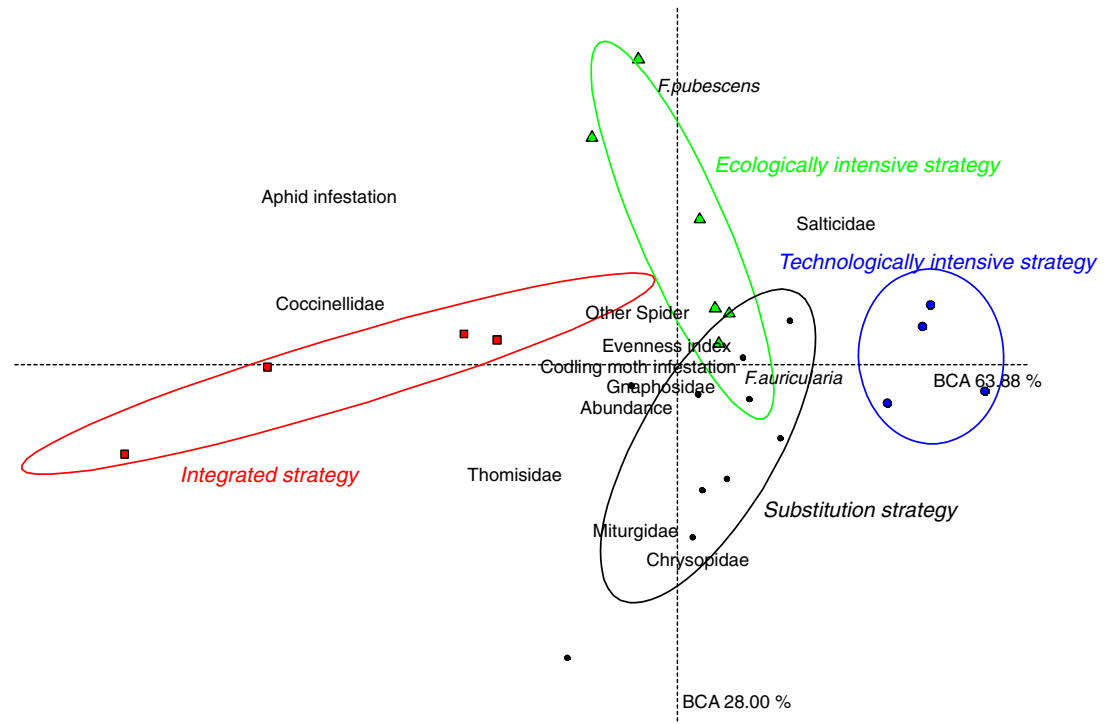




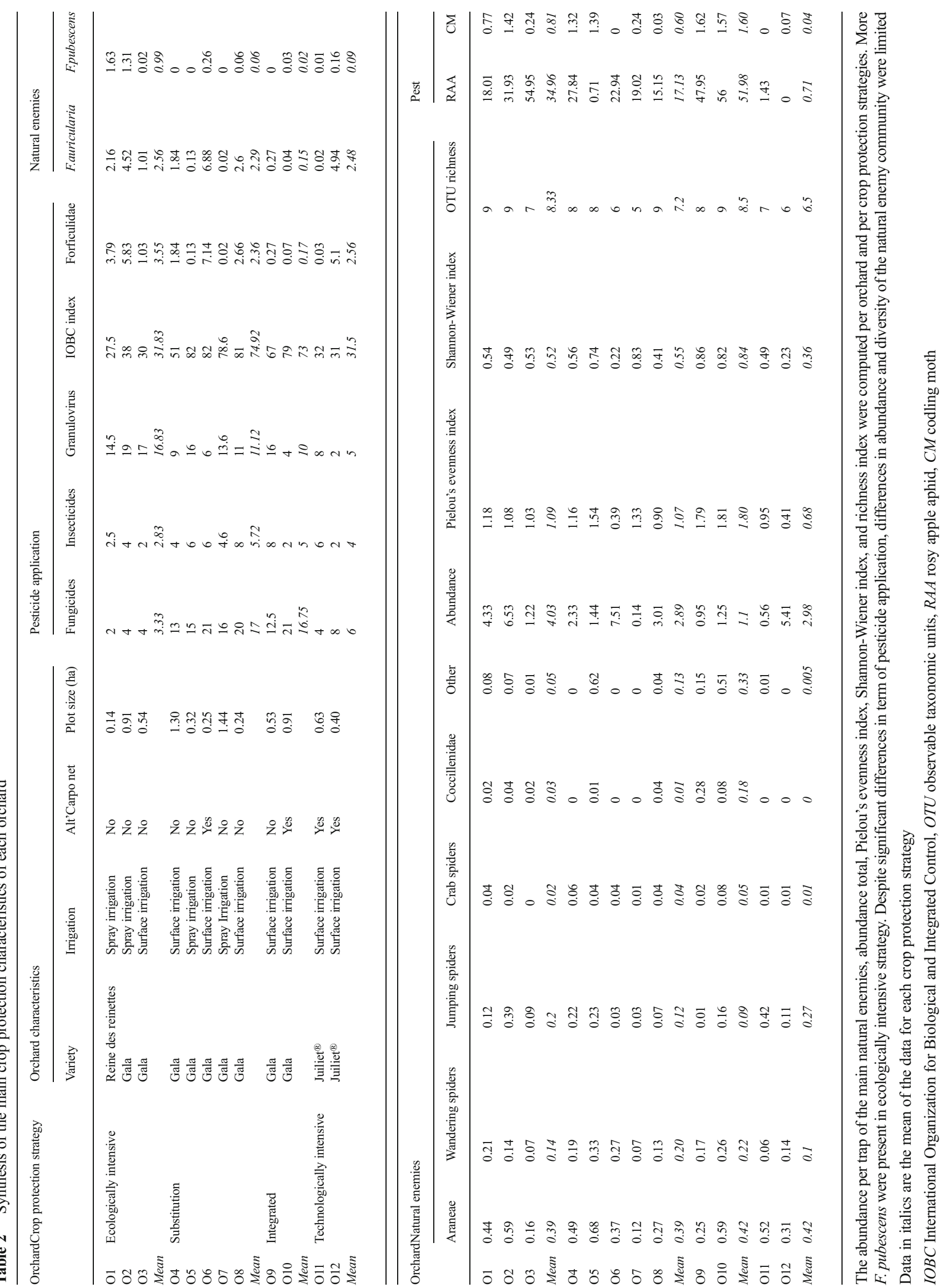


predation is decreased in more complex structures (Finke and Denno 2003). Moreover, the frequent hedgerows around the orchards provide habitats and resources for natural enemies and can represent a refuge when pesticides are applied in the orchard (Rieux et al. 1999).

\section{Conclusions}

Our study showed that within organic farms and at the regional level, four crop protection strategies coexist that differ not only in pesticide usage but also in the combination and priority given to protection methods. The ecologically intensive strategy was defined by the implementation of consistent practices to promote biological control by natural enemies; farmers were driven by their objective to reduce environmental impacts. The integrated strategy implemented the largest combination of practices. In the substitution strategy, a limited combination of direct control methods focused on pesticide applications was used; the farmers chose a crop protection strategy in order to limit economic risk. The technologically intensive strategy was also defined by a limited combination focusing on recent technological methods. These crop protection strategies displayed different pesticide application patterns and IOBC toxicity levels. A reduction in pesticide use was observed in the technologically intensive strategy which applied a resistant cultivar and Alt'Carpo exclusion nets.

The community of natural enemies was also different depending on the organic crop protection strategies in the orchards. F. pubescens may be a bioindicator of the crop protection strategy with low environmental impact. To increase natural enemies in organic farming, the ecologically intensive and integrated strategies showed interesting results, but this must be further analyzed with regards to pest infestation and colonization dynamics and natural enemy functional traits. Future studies should focus on the function of these natural enemies and the impact of the organic crop protection strategies on the pest regulation.

In summary, in future studies, it would be important to consider organic systems not as a unique system but as a combination of different practices. The classical dichotomy of conventional versus organic agriculture must be revisited in light of these results. Further studies will explore the impact of this "new classification" on ecosystem services, especially pest regulation.

Acknowledgments The authors wish to thank local institutions (Chamber of Agriculture and advice organizations) for giving their time and farmers who took part in the survey. We also thank Jean-François Toubon for facilitating contact with organic apples growers. The $\mathrm{PhD}$ fellowship of the first author was jointly financed by the DynRurABio program and the Smach metaprogram.

\section{References}

Agence bio (2012) http://www.agencebio.org/la-bio-en-France. Accessed 20 September 2013

Agreste (2014) http://agreste.agriculture.gouv.fr/. Accessed 20 September 2013

Arthurs SP, Lacey LA, Miliczky ER (2007) Evaluation of the codling moth granulovirus and spinosad for codling moth control and impact on non-target species in pear orchards. Biol Control 41(1):99-109. doi:10.1016/j.biocontrol.2007.01.001

Bengtsson J, AhnstrÖM J, Weibull A-C (2005) The effects of organic agriculture on biodiversity and abundance: a meta-analysis. J Appl Ecol 42(2):261-269. doi:10.1111/j.1365-2664.2005.01005.x

Borcard D, Gillet F, Legendre P (2011) Numerical ecology with R. Springer New York

Brown MW (1999) Applying principles of community ecology to pest management in orchards. Agric Ecosyst Environ 73(2):103-106. doi:10.1016/S0167-8809(99)00018-3

Bürger J, Günther A, de Mol F, Gerowitt B (2012) Analysing the influence of crop management on pesticide use intensity while controlling for external sources of variability with linear mixed effects models. Agric Syst 111:13-22. doi:10.1016/j.agsy.2012.05.002

Chessel D, Dufour A-B, Thioulouse J (2004) The ade4 package-I: onetable methods. R News 4:5-10

Finke DL, Denno RF (2003) Intra-guild predation relaxes natural enemy impacts on herbivore populations. Ecol Entomol 28(1):67-73. doi: 10.1046/j. 1365-2311.2003.00475.x

Garratt MPD, Wright DJ, Leather SR (2011) The effects of farming system and fertilisers on pests and natural enemies: a synthesis of current research. Agric Ecosyst Environ 141(3-4):261-270. doi:10. 1016/j.agee.2011.03.014

Grechi I, Sauge M-H, Sauphanor B, Hilgert N, Senoussi R, Lescourret F (2008) How does winter pruning affect peach tree-Myzus persicae interactions? Entomol Exp Appl 128(3):369-379. doi:10.1111/j. 1570-7458.2008.00720.x

Hill SB, Vincent C, Chouinard G (1999) Evolving ecosystems approaches to fruit insect pest management. Agric Ecosyst Environ 73(2):107-110. doi:10.1016/s0167-8809(99)00019-5

Hole DG, Perkins AJ, Wilson JD, Alexander IH, Grice F, Evans AD (2005) Does organic farming benefit biodiversity? Biol Conserv 122(1):113-130. doi:10.1016/j.biocon.2004.07.018

Hubbell BJ, Carlson GA (1998) Effects of insecticide attributes on within-season insecticide product and rate choices: the case of U.S. apple growers. Am J Agric Econ 80(2):382-396. doi:10. $2307 / 1244510$

Jørgensen L (1999) Denmark's action plans for pesticides: status and role of research. Nord Jordbrugsforskning 81:201-202

Landis DA, Wratten SD, Gurr GM (2000) Habitat management to conserve natural enemies of arthropod pests in agriculture. Annu Rev Entomol 45:175-201. doi:10.1146/annurev.ento.45.1.175

Lebart L, Morineau A, Piron M (1997) Statistique exploratoire multidimensionnelle. Dunod Paris

Letourneau DK, Bothwell SG (2008) Comparison of organic and conventional farms: challenging ecologists to make biodiversity functional. Front Ecol Environ 6(8):430-438. doi:10.1890/070081

Lohr L, Park TA (2002) Choice of insect management portfolios by organic farmers: lessons and comparative analysis. Ecol Econ 43(1):87-99. doi:10.1016/S0921-8009(02)00184-2

Markó V, Blommers LHM, Bogya S, Helsen H (2008) Kaolin particle films suppress many apple pests, disrupt natural enemies and promote woolly apple aphid. J Appl Entomol 132(1):26-35. doi:10. 1111/j.1439-0418.2007.01233.x

Monteiro LB, Lavigne C, Ricci B, Franck P, Toubon J-F, Sauphanor B (2013) Predation of codling moth eggs is affected by pest 
management practices at orchard and landscape levels. Agric Ecosyst Environ. doi:10.1016/j.agee.2011.10.012

Oksanen J, Kindt R, Legendre P, O'Hara B, Stevens MHH, Oksanen MJ, Suggests M (2007) The vegan package. Community ecology package

Pekár S (1999) Some observations on overwintering of spiders (Araneae) in two contrasting orchards in the Czech Republic. Agric Ecosyst Environ 73(3):205-210. doi:10.1016/S0167-8809(99)00052-3

Penvern S, Bellon S, Fauriel J, Sauphanor B (2010) Peach orchard protection strategies and aphid communities: towards an integrated agroecosystem approach. Crop Prot 29(10):1148-1156. doi:10. 1016/j.cropro.2010.06.010

Pfiffner L, Niggli U (1996) Effects of bio-dynamic, organic and conventional farming on ground beetles (Col. Carabidae) and other epigaeic arthropods in winter wheat. Biol Agric Hortic 12(4):353-364. doi: 10.1080/01448765.1996.9754758

Piñol J, Espadaler X, Pérez N, Beven K (2009) Testing a new model of aphid abundance with sedentary and non-sedentary predators. Ecol Model 220(19):2469-2480

Puech C, Baudry J, Joannon A, Poggi S, Aviron S (2014) Organic vs. conventional farming dichotomy: does it make sense for natural enemies? Agric Ecosyst Environ 194:48-57. doi:10.1016/j.agee. 2014.05.002

R Development Core Team (2010) R: a language and environment for statistical computing. R Foundation for Statistical Computing, Vienna

Rana JS, Dixon AFG, Jarošík V (2002) Costs and benefits of prey specialization in a generalist insect predator. J Anim Ecol 71(1):15-22. doi:10.1046/j.0021-8790.2001.00574.x

European Union: Regulation (EC) No. 889/2008 laying down detailed rules for the implémentation of Council Regulation (EC) No.834/ 2007 on organic production and labelling of organic products with regard to organic production, labelling and control. Off J EU, L250/ $1-\mathrm{L} 250 / 84$

Rieux R, Simon S, Defrance H (1999) Role of hedgerows and ground cover management on arthropod populations in pear orchards. Agric Ecosyst Environ 73(2):119-127. doi:10.1016/S0167-8809(99) 00021-3

Sauphanor B, Dirwimmer C, Boutin S, Chaussabel A, Dupont N, Fauriel J, Gallia V, Lambert N, Navarro E, Parisi L, Plenet D, Ricaud V, Sagnes J, Sauvaitre D, Simon S, Speich P, Zavagli F (2009) Analyse comparative de différents systèmes en arboriculture fruitière. In: INRA (ed) Ecophyto R\&D: vers des systèmes deculture économes en produits phytosanitaires. Rapport d'Expertise Collective Inra, Tome I
Sauphanor B, Severac G, Maugin S, Toubon JF, Capowiez Y (2012) Exclusion netting may alter reproduction of the codling moth (Cydia pomonella) and prevent associated fruit damage to apple orchards. Entomol Exp Appl 145(2):134-142. doi:10.1111/j.15707458.2012.01320.x

Simon S, Bouvier J-C, Debras J-F, Sauphanor B (2010) Biodiversity and pest management in orchard systems. A review. Agron Sustain Dev 30(1):139-152. doi:10.1051/agro/2009013

Simon S, Brun L, Guinaudeau J, Sauphanor B (2011) Pesticide use in current and innovative apple orchard systems. Agron Sustain Dev 31(3):541-555. doi:10.1007/s13593-011-0003-7

Suckling DM, Walker JTS, Wearing CH (1999) Ecological impact of three pest management systems in New Zealand apple orchards. Agric Ecosyst Environ 73(2):129-140. doi:10.1016/s01678809(99)00022-5

Tassoni A, Tango N, Ferri M (2013) Comparison of biogenic amine and polyphenol profiles of grape berries and wines obtained following conventional, organic and biodynamic agricultural and oenological practices. Food Chem 139(1-4):405-413. doi:10.1016/j.foodchem. 2013.01.041

Theiling K, Croft B (1988) Pesticide side-effects on arthropod natural enemies: a database summary. Agric Ecosyst Environ 21:191-218. doi:10.1016/0167-8809(88)90088-6

Thomson LJ, Hoffmann AA (2006) Field validation of laboratoryderived IOBC toxicity ratings for natural enemies in commercial vineyards. Biol Control 39(3):507-515. doi:10.1016/j.biocontrol. 2006.06.009

Tscharntke T, Klein AM, Kruess A, Steffan-Dewenter I, Thies C (2005) Landscape perspectives on agricultural intensification and biodiversity-ecosystem service management. Ecol Lett 8(8):857-874. doi: 10.1111/j.1461-0248.2005.00782.x

Ward JH Jr (1963) Hierarchical grouping to optimize an objective function. J Am Stat Assoc 58(301):236-244. doi:10.1080/01621459. 1963.10500845

Winqvist C, Bengtsson J, Aavik T, Berendse F, Clement LW, Eggers S, Fischer C, Flohre A, Geiger F, Liira J, Pärt T, Thies C, Tscharntke T, Weisser WW, Bommarco R (2011) Mixed effects of organic farming and landscape complexity on farmland biodiversity and biological control potential across Europe. J Appl Ecol 48(3):570-579. doi:10. $1111 / j .1365-2664.2010 .01950 . x$

Wyss E, Luka H, Pfiffner L, Schlatter C, Gabriela U \& Daniel C (2005) Approaches to pest management in organic agriculture: a case study in European apple orchards. Cab International: Organic-Research. com May 2005, 33N-36N 